\title{
Asia's Regional Architecture: Alliances and Institutions in the Pacific Century. By Andrew Yeo. Stanford, California: Stanford University Press, 2019. Hardcover: 243pp.
}

Asia—and its broader nomenclature the "Indo-Pacific"-has arguably emerged as the most important and dynamic region in the world. It is the vortex of global competition between the world's established superpower, the United States, and its rising one, China. Speculation is growing within official circles and among independent observers of international relations about what type of order-if any-is now emerging. Predicting a specific outcome of any order-building process seems hazardous at best, but especially so in an era of widespread populism, economic unpredictability and intensifying multipolarity. Yet what happens in this region will largely shape the next phase of world history. In an era of competition between President Donald Trump's “America First” and President Xi Jinping's "Chinese Dream”, there seems to be little room for compromise and thus an inordinate danger for tragic strategic miscalculations which could precipitate existential crises and conflicts.

In this context, a book focusing on the evolution and nature of Asia's "regional architecture" would initially seem to be a somewhat abstract, if not largely outdated, enterprise. Not so argues its author, Andrew Yeo. He insists that applying insights of "historical institutionalism" will enable social scientists and others to better account for change and continuity in our time.

Yeo undertakes a highly ambitious and sophisticated analytical task, combining theoretical perspectives on liberal institutions and alliances with a comprehensive empirical analysis of bilateral and multilateral security politics in East Asia. He posits a liberal institutionalist argument: that the institutional arrangements found in this region are more powerful and resilient than the whims of any individual leader (i.e. Trump) and thus "reflect greater stability and continuity than perhaps recent political commentators have assumed" (p. 2). Nevertheless, he qualifies this approach by acknowledging that realists may well be correct in asserting that the Indo-Pacific currently is "rife with mistrust, nationalistic passions, and spiraling arms races" which could eventually lead to widespread regional fragmentation and instability (pp. 2-3). These two paradigms, however, are not mutually exclusive. Applying historical institutionalism to gain a better understanding of how "regional architecture" shapes regional order in this part of the world represents a promising conceptual 
tool for policymakers and independent observers to integrate these two outlooks' most relevant perspectives.

This work is generally well-organized in terms of both its research design and presentation of specific chapters devoted to both the bilateral and multilateral dynamics shaping contemporary order-building in the region. It effectively tells the story of how US bilateral alliances have adapted in the post-Cold War strategic regional environment and demonstrates how newer regional institutions have often complemented this bilateral "hub and spokes" arrangement to maintain — at least until recently—a relatively benign Indo-Pacific environment. It employs qualitative methodology in the form of case study analysis, focusing on three distinct timeframes that highlight the nature of institutional evolution: the inception of the Indo-Pacific's post-Cold War strategic evolution (1989-97, Chapter Three); the apex of multilateral institution-building to address regional economic and politico-security challenges (19982007, Chapter Four); and the (tacit) integration of bilateral and multilateral security politics in ways that the two "layers" have come to overlap and, indeed, in various instances, complement one another (2008-17, Chapter Five).

Chapter Six reflects the author's attempt to deal with both the Trump administration's challenge to liberal order-building in the region and the growing Chinese role in defining and shaping new Asian architectures. The latter implies the development of a very different model of regional order-building than the one which has predominated over the previous quarter century. The assessments presented on the Trump administration's specific track record, and on China's specific institutional policy objectives, are quite sparse (about five pages each) relative to the entire book's length. That more extensive analysis is not conveyed on the Trump administration's approach is understandable, given the time between Trump assuming office and the book's publication. The China discussion could have benefitted from a more wide-ranging discussion of why Xi's China shifted away from its "panda diplomacy" to a more aggressive posture around 2011-12. The three "scenarios of Asian order" introduced in the middle of Chapter Six ("modified liberal order", "China-dominated order" and "multiple orders") were suitable for encapsulating the intricacies of "complex patchworks" (terminology the author borrowed from Victor Cha but has refined usefully). But they may have been better placed in what seems to be an all too short Conclusion (Chapter Seven runs to only around twelve pages of text) as an empirical offset and interesting offshoot to an otherwise 
comparatively dry effort to resurrect historical institutionalism as the book's main focal point.

Overall, Yeo has produced a very timely and valuable contribution to the expanding literature on regional institutions and their security implications in the Indo-Pacific region. The book has earned a place on the reserve reading list of both undergraduate and postgraduate courses addressing Asian politics and security. It will be equally useful for both policy officials and interested observers of Asian affairs to consult.

William T. Tow is Professor of International Relations, Australian National University, Canberra. Postal address: Department of International Relations, Coral Bell School of Asia-Pacific Studies, College of Asia and the Pacific (CAP), The Australian National University, Canberra, ACT 2601, Australia; email: william.tow@anu. edu.au. 